\title{
Nature and frequency of respiratory involvement in chronic progressive external ophthalmoplegia
}

\author{
Bart W. Smits $\cdot$ Yvonne F. Heijdra • \\ Femke W. A. Cuppen • Baziel G. M. van Engelen
}

Received: 4 November 2010/Revised: 12 April 2011/Accepted: 12 April 2011/Published online: 1 May 2011

(C) The Author(s) 2011. This article is published with open access at Springerlink.com

\begin{abstract}
Chronic progressive external ophthalmoplegia (CPEO) is a relatively common mitochondrial disorder. Weakness of the extra-ocular, limb girdle and laryngeal muscles are established clinical features. Respiratory muscle involvement however has never been studied systematically, even though respiratory complications are one of the main causes of death. We therefore determined the prevalence and nature of respiratory muscle involvement in 23 patients with genetically confirmed CPEO. The main finding was decreased respiratory muscle strength, both expiratory ( $76.8 \%$ of predicted, $p=0.002)$ and inspiratory (79.5\% of predicted, $p=0.004)$. Although the inspiratory vital capacity $(92.5 \%$ of predicted, $p=0.021)$ and the forced expiratory volume in $1 \mathrm{~s}(89.3 \%$ of predicted, $p=0.002$ ) were below predicted values, both were still within the normal range in the majority of patients. Expiratory weakness was associated with a decreased vital capacity $(\rho=0.502, p=0.015)$ and decreased peak expiratory flow $(\rho=0.422, \quad p=0.045)$. Moreover, expiratory muscle strength was lower in patients with limb girdle weakness $(62.6 \pm 26.1 \%$ of predicted vs. $98.9 \pm 22.5 \%$ in patients with normal limb girdle strength, $p=0.003$ ), but was not associated with other clinical features, subjective respiratory complaints, disease severity or disease duration. Since respiratory involvement in CPEO is associated with severe morbidity and mortality,
\end{abstract}

B. W. Smits $(\bowtie)$ - B. G. M. van Engelen

Neuromuscular Centre Nijmegen, Department of Neurology, Radboud University Nijmegen Medical Centre,

Reinier Postlaan 4, 6500 HB Nijmegen, The Netherlands

e-mail: b.smits@neuro.umcn.nl

Y. F. Heijdra · F. W. A. Cuppen

Department of Pulmonary Diseases, Radboud University

Nijmegen Medical Centre, Nijmegen, The Netherlands the present data justify periodic assessment of respiratory functions in all CPEO patients.

Keywords Chronic progressive external ophthalmoplegia $\cdot$ Kearns-Sayre syndrome . Respiratory muscles · Pneumonia $\cdot$ Polymerase gamma

\section{Introduction}

Chronic progressive external ophthalmoplegia (CPEO) is one of the most common mitochondrial disorders in adults [1]. The characteristic clinical feature is a slowly progressive weakness of the extraocular muscles, resulting in ptosis and restriction of eye movements [5]. CPEO is however often a multi-system disorder, affecting the limb girdle and laryngeal muscles, retina, cochlea, cerebrum, cerebellum or heart. The prevalence and nature of respiratory involvement have never been systematically studied.

Two cohort studies have shown that respiratory complications are one of the main causes of death in CPEO [2, 12]. Conversely, studies that specifically investigated respiratory function in CPEO are limited to case reports and studies on small series of patients without a genetically confirmed diagnosis [3, 7, 8, 11, 15, 19]. Most consistent findings were a decreased ventilatory drive to hypoxia and hypercapnia and respiratory muscle weakness. However, the prevalence, nature and determinants of respiratory involvement in CPEO cannot be reliably determined from these uncontrolled studies. More insight into the nature of respiratory involvement is nevertheless desirable, since it may help to prevent respiratory complications and respiration-related deaths [12].

In a large cohort of genetically confirmed CPEO patients, we performed an extensive standardized 
assessment of respiratory muscle function, including spirometry, measurement of respiratory muscle strength and of diffusion capacity. In order to identify possible determinants of respiratory muscle involvement, patients also completed questionnaires on subjective respiratory symptoms and underwent a standardized neurological examination.

\section{Methods}

Patients

All CPEO patients known in the Department of Neurology of the Radboud University Nijmegen Medical Centre were invited to participate. As there are no commonly accepted criteria for CPEO, we only included patients with both characteristic clinical features and a known causative mutation. Consequently, all participants met the following three criteria:

1. a phenotype including a slowly progressive bilateral external ophthalmoplegia

2. a proven pathogenic mutation or deletion in the mitochondrial DNA (mtDNA) or in the nuclear polymerase gamma 1 (POLG1), Twinkle or adenine nucleotide translocator 1 (ANT1) genes

3. exclusion of an alternative diagnosis.

These inclusion criteria also cover two more or less specific mitochondrial phenotypes with external ophthalmoplegia as a key symptom: the Kearns-Sayre syndrome (KSS: external ophthalmoplegia, pigmented retinopathy, age of onset below 20 years and at least one of the following symptoms: cardiac conduction block, cerebellar ataxia, elevated CSF protein content) [14] and SANDO (Sensoric Atactic Neuropathy, Dysarthria and Ophthalmoplegia) $[4,9]$. In this article, we use the term CPEO to describe all patients meeting the inclusion criteria, and the terms KSS and SANDO to describe the specific phenotypes only.

All participants gave informed consent. The local ethics committee approved this study, and the patients' consent was obtained according to the Declaration of Helsinki.

Methods

\section{Patients' characteristics}

We performed a standardized neurological examination, including an assessment of muscle strength (ocular, bulbar and extremities), sensory functions, tendon reflexes and coordination. We also measured the length, and weight and calculated the body mass index. Results of ancillary investigations and of genetic investigations were derived from the patients' files.

\section{Subjective complaints}

All participants completed a questionnaire with items on history of smoking and pulmonary disease, dyspnea, swallowing, coughing and quality of sleep. We assessed the level of independence in daily activities using the modified Rankin score (mRS), with an $\mathrm{mRS} \leq 2$ indicating independence [23].

\section{Pulmonary function tests}

All eligible patients were invited to undergo respiratory function tests in our pulmonary function department. To exclude a possible selection bias (patients who were unable to visit our hospital might have more advanced disease), we offered to perform respiratory function tests at home for those patients who were willing to participate but could not visit our hospital.

Respiratory function tests were performed according the American Thoracic Society/European Respiratory Society standards [17]. First, we measured respiratory muscle strength, including the maximal expiratory mouth pressure (PE-Max), and the maximal inspiratory mouth pressure (PI-Max). Next, to evaluate the effect of respiratory muscle weakness on the inspiratory vital capacity (IVC), we performed spirometry, including the forced expiratory volume in $1 \mathrm{~s}$ (FEV1), the FEV1/IVC ratio, the peak expiratory flow (PEF) and the forced inspiratory volume in $1 \mathrm{~s}$ (FIV1). We also measured the total lung capacity (TLC), the diffusion capacity for carbon monoxide (TLCO) and the diffusion capacity for carbon monoxide corrected for alveolar volume (KCO).

All tests were performed by a trained pulmonary function technician. The TLC, FIV1, TLCO and KCO could not be measured at the patients' homes and were therefore measured in patients visiting our hospital only.

Statistical analysis

Data analysis was performed using SPSS (version 17.0). To assess the extent of pulmonary involvement in CPEO we compared the test results of the individual participants to their own predicted values using a paired Wilcoxon signed ranks test. For comparison between various subgroups, we performed an independent Mann-Whitney $U$ test on the test results relative to the predicted values, which are noted as "value \% pred": for example, "IVC" indicates the inspiratory vital capacity (in liters), whereas "IVC\% pred" indicates the inspiratory vital capacity relative to the predicted value (in \%). A Fisher's exact test was used to 
Table 1 Demographical, genetic and clinical results of 23 CPEO patients

\begin{tabular}{|c|c|c|c|c|c|c|c|c|c|}
\hline No. & $\begin{array}{l}\text { Sex/age/age } \\
\text { at onset }\end{array}$ & Mutation & $\begin{array}{l}\text { Smoking } \\
\text { history }\end{array}$ & $\begin{array}{l}\text { Pulmon. } \\
\text { history }\end{array}$ & $\begin{array}{l}\text { CNS } \\
\text { involv. }\end{array}$ & $\begin{array}{l}\text { Limb } \\
\text { girdle }\end{array}$ & $\begin{array}{l}\text { Periph. } \\
\text { neurop. }\end{array}$ & $\begin{array}{l}\text { Dysarthria/ } \\
\text { dysphagia }\end{array}$ & Other \\
\hline 1 & $F / 28 / 21$ & Deletion & $\mathrm{C}$ & - & - & - & - & $-1-$ & \\
\hline 2 & $F / 43 / 32$ & Deletion & - & - & - & - & - & $-1-$ & PHL, HT \\
\hline 3 & F/29/17 & Deletion & $\mathrm{C}$ & $\mathrm{P}$ & - & + & - & $-1+$ & \\
\hline 4 & $\mathrm{~F} / 35 / 14$ & Deletion & - & - & M & - & - & $-1-$ & \\
\hline 5 & $\mathrm{M} / 32 / 8$ & Deletion & - & - & CA, CI & + & - & $-1+$ & PHL, RI \\
\hline 6 & $\mathrm{~F} / 52 / 25$ & Deletion & - & - & - & + & - & $-1-$ & \\
\hline 7 & $\mathrm{~F} / 62 / 34$ & Deletion & $\mathrm{F}$ & - & CA, CI, E & + & - & $-1-$ & $\mathrm{CM}$ \\
\hline 8 & $\mathrm{~F} / 43 / 15$ & Deletion & $\mathrm{C}$ & - & - & + & - & $+/+$ & \\
\hline 9 & $\mathrm{M} / 54 / 25$ & Deletion & $\mathrm{F}$ & - & - & + & - & $+/+$ & \\
\hline 10 & $\mathrm{M} / 40 / 11$ & Deletion & $\mathrm{C}$ & - & - & - & - & $-1-$ & \\
\hline 11 & $\mathrm{M} / 45 / 14$ & Deletion & $\mathrm{F}$ & - & $\mathrm{CA}, \mathrm{CI}$ & + & - & $+/+$ & CB, PHL, RI \\
\hline 12 & $\mathrm{~F} / 54 / 13$ & Deletion & $\mathrm{F}$ & - & - & + & - & $-1-$ & \\
\hline 13 & $\mathrm{~F} / 61 / 17$ & Deletion & $\mathrm{F}$ & - & - & - & - & $-1-$ & \\
\hline 14 & $\mathrm{M} / 63 / 12$ & Deletion & - & $\mathrm{P}$ & - & + & - & $+/+$ & \\
\hline 15 & $\mathrm{M} / 55 / 48$ & $\mathrm{~m} .4267 \mathrm{~A}>\mathrm{G}$ & - & - & - & + & - & $-1-$ & \\
\hline 16 & $\mathrm{M} / 66 / 36$ & m.12315G $>A$ & - & - & - & - & - & $-1-$ & \\
\hline 17 & $\mathrm{~F} / 54 / 12$ & $\mathrm{~m} .3243 \mathrm{~A}>\mathrm{G}$ & $\mathrm{F}$ & $\mathrm{A}, \mathrm{P}$ & $\mathrm{CA}, \mathrm{M}$ & + & - & $+/-$ & PHL, RI, DM \\
\hline 18 & $\mathrm{M} / 57 / 12$ & $\mathrm{~m} .3243 \mathrm{~A}>\mathrm{G}$ & $\mathrm{C}$ & A & CI & - & + & $-1-$ & PHL, DM \\
\hline 19 & $\mathrm{M} / 63 / 53$ & POLG1 & - & - & - & - & + & $-1-$ & \\
\hline 20 & $\mathrm{M} / 52 / 39$ & POLG1 & - & - & CA, CI & + & SAN & $+/-$ & PHL, RI \\
\hline 21 & $\mathrm{M} / 43 / 23$ & POLG1 & - & - & CA, CI & + & SAN & $+/+$ & PHL, RI \\
\hline 22 & $\mathrm{~F} / 51 / 24$ & POLG1 & - & A, P & CA & + & SAN & $+/+$ & PHL \\
\hline 23 & $\mathrm{M} / 48 / 21$ & POLG1 & - & - & CA, CI & - & SAN & $+/+$ & PHL, RI \\
\hline
\end{tabular}

$C N S$ central nervous system, $P O L G 1$ polymerase gamma $1, C$ current smoker, $F$ former smoker, $P$ pneumonia, $A$ asthma, $M$ migraine, $C A$ cerebellar ataxia, $C I$ cognitive impairment, $E$ epilepsy, $S A N$ sensoric atactic neuropathy, $C M$ cardiomyopathy, $C B$ cardiac conduction block, $P H L$ peripheral hearing loss, $R I$ retinal involvement, $D M$ diabetes mellitus, $H T$ hypothyroidism

compare frequencies and a Spearman coefficient to calculate correlations. The significance level was set at $p<0.05$ (two-tailed) in all cases.

\section{Results}

\section{Patients' characteristics}

We identified 26 eligible patients. All were invited to participate; two patients refused (one male patient with an m.12315G > A mutation and one female patient with a mtDNA deletion). In general, their clinical features and disease severity were in the same range as the participants. During the tests, one of the participants appeared to be unable to follow the instructions because of severe vision and hearing impairments. Her test results were unreliable and therefore excluded from all analyses. Of the remaining 23 patients ( 11 female, 12 male), 14 (60.9\%) were tested in the pulmonary function department and $9(39.1 \%)$ at home. Mean age of the participants was $49.1 \pm 11.0$ years, and mean age at onset was $22.9 \pm 12.2$ years (Table 1). Mutation type included a single mtDNA deletion in 14 patients $(60.9 \%)$, a mtDNA point mutation in $4(17.4 \%)$ and a POLG1 mutation in $5(21.7 \%)$. POLG1 mutations included compound heterozygous T251I, P587L and A957S mutations in one patient (patient 19), a homozygous A467T in two patients (patients 20 and 21), and compound heterozygous A467T and W748S mutations in two (patients 22 and 23). Three patients (19, 20 and 23) also had multiple mtDNA deletions in their skeletal muscle mtDNA. None of the patients had Twinkle or ANT1 mutations. One patient (with a mtDNA deletion) met the criteria for KSS [14] and four (all with POLG1 mutations) for SANDO. Fifteen patients $(65.2 \%)$ were independent in daily life activities, whereas eight (34.7\%) were not.

\section{Questionnaires}

Five patients $(21.7 \%)$ were current smokers, and 6 of the remaining 18 patients $(33.3 \%)$ were former smokers 
Table 2 Results of respiratory function assessment

\begin{tabular}{|c|c|c|c|c|c|c|c|c|c|c|c|}
\hline No. & BMI & PE-Max & PI-Max & IVC & TLC & FEV1 & FEV1/IVC & PEF & FIV1 & TLCO & $\mathrm{KCO}$ \\
\hline 1 & 24.7 & 9.4 (101) & $8.0(109)$ & $3.8(100)$ & $4.7(91)$ & $3.3(101)$ & 87 & $9.0(125)$ & $3.3(94)$ & $8.9(94)$ & 2.0 (109) \\
\hline 2 & 34.7 & $11.6(118)$ & 8.3 (104) & 4.7 (121) & $6.2(108)$ & 3.7 (115) & 80 & $8.0(110)$ & 4.5 (128) & $8.2(86)$ & $1.4(87)$ \\
\hline 3 & 16.8 & $4.0(45)$ & $5.1(74)$ & $2.1(61)$ & $4.3(89)$ & $2.0(68)$ & 95 & $5.2(76)$ & $2.0(60)$ & $6.9(77)$ & $1.8(94)$ \\
\hline 4 & 23.5 & $9.5(95)$ & $6.6(79)$ & $3.8(90)$ & $5.1(83)$ & $3.3(92)$ & 87 & 8.0 (103) & 3.7 (93) & $7.0(68)$ & $1.6(94)$ \\
\hline 5 & 17.9 & $7.7(52)$ & $7.2(67)$ & $4.0(92)$ & $4.9(84)$ & $3.1(87)$ & 78 & $7.8(89)$ & $3.8(94)$ & $7.2(73)$ & $1.5(90)$ \\
\hline 6 & 34.4 & $4.3(46)$ & $5.4(73)$ & $2.5(77)$ & & $2.1(79)$ & 85 & $5.6(85)$ & & & \\
\hline 7 & 30.0 & $7.3(74)$ & $5.4(66)$ & 3.9 (111) & 6.9 (116) & $2.6(87)$ & 67 & $8.3(121)$ & 3.8 (118) & 7.8 (89) & $1.3(86)$ \\
\hline 8 & 19.0 & $2.8(30)$ & $3.7(50)$ & $2.9(84)$ & $4.5(86)$ & $2.6(90)$ & 95 & $6.2(91)$ & $2.4(77)$ & $6.5(74)$ & $1.6(95)$ \\
\hline 9 & 27.8 & 2.4 (19) & $1.7(20)$ & $4.4(86)$ & & $3.5(91)$ & 81 & $6.8(74)$ & & & \\
\hline 10 & 27.3 & $10.7(75)$ & $4.4(44)$ & $4.8(82)$ & $6.1(75)$ & $3.7(81)$ & 77 & $10.0(99)$ & $4.3(81)$ & $10.0(80)$ & 1.7 (112) \\
\hline 11 & 18.9 & $6.9(51)$ & $10.2(109)$ & $4.8(100)$ & & 3.8 (103) & 81 & $9.0(100)$ & & & \\
\hline 12 & 21.8 & $5.1(52)$ & $5.0(63)$ & 3.7 (105) & $5.3(94)$ & $2.9(98)$ & 77 & $6.8(100)$ & $3.6(113)$ & $7.3(74)$ & $1.5(97)$ \\
\hline 13 & 30.1 & 10.6 (116) & $8.0(112)$ & 3.2 (109) & $4.4(89)$ & $2.3(97)$ & 78 & 7.1 (117) & 2.9 (112) & $5.6(73)$ & $1.4(89)$ \\
\hline 14 & 25.9 & $7.2(60)$ & $2.7(35)$ & 3.7 (79) & & $2.7(76)$ & 72 & $5.5(64)$ & & & \\
\hline 15 & 25.3 & 12.7 (99) & $8.2(97)$ & $5.1(120)$ & $6.8(103)$ & 4.5 (135) & 87 & 11.9 (142) & $5.0(130)$ & $9.5(101)$ & $1.5(104)$ \\
\hline 16 & 24.2 & $10.1(86)$ & $5.0(68)$ & $2.8(80)$ & & $2.3(84)$ & 80 & $7.6(103)$ & & & \\
\hline 17 & 23.0 & $7.7(80)$ & $8.1(105)$ & 3.8 (109) & $5.3(95)$ & $2.3(80)$ & 61 & $5.6(83)$ & 3.4 (111) & $7.6(79)$ & $1.5(97)$ \\
\hline 18 & 16.9 & $8.4(66)$ & $8.2(99)$ & $3.5(72)$ & & $2.6(70)$ & 75 & $6.2(70)$ & & & \\
\hline 19 & 29.1 & 16.5 (138) & $8.2(110)$ & 3.7 (92) & $6.4(97)$ & $2.1(68)$ & 56 & $5.9(75)$ & 3.5 (98) & 9.4 (107) & $1.8(132)$ \\
\hline 20 & 24.4 & $9.0(69)$ & $8.0(91)$ & $3.6(81)$ & & $2.8(81)$ & 80 & $8.1(94)$ & & & \\
\hline 21 & 18.0 & $12.3(89)$ & $6.4(67)$ & $5.3(94)$ & 7.9 (99) & $4.1(94)$ & 78 & 9.7 (99) & $5.1(98)$ & $8.6(71)$ & $1.3(83)$ \\
\hline 22 & 21.5 & 10.7 (111) & 8.9 (116) & $3.5(101)$ & & $2.6(90)$ & 74 & $5.6(83)$ & & & \\
\hline 23 & 27.2 & $12.7(95)$ & $6.6(73)$ & $4.4(82)$ & & $3.6(87)$ & 82 & $9.1(95)$ & & & \\
\hline Mean & & 8.68 & 6.49 & 3.82 & 5.63 & 2.97 & 79 & 7.52 & 3.66 & 7.89 & 1.56 \\
\hline SD & & 3.49 & 2.13 & 0.80 & 1.11 & 0.70 & 9.2 & 1.73 & 0.88 & 1.27 & 0.20 \\
\hline$\%$ pred. & & $76.8 * *$ & $79.5^{* *}$ & $92.5^{*}$ & 93.6 & $89.3 * *$ & 99.5 & 95.6 & 100.5 & $81.9^{* *}$ & 97.9 \\
\hline
\end{tabular}

In value (percentage of predicted). Blank fields indicate that the patient was tested at home and as a result the specific test was not performed $B M I$ body mass index (in $\mathrm{kg} / \mathrm{m}^{2}$ ), $P E-$ Max maximal expiratory mouth pressure (in $\mathrm{kPa}$ ), PI-Max maximal inspiratory mouth pressure (in $\mathrm{kPa}$ ), $I V C$ inspiratory vital capacity (in liters), $T L C$ total lung capacity (in liters), FEVI forced expiratory volume in $1 \mathrm{~s}$ (in liters), $P E F$ peak expiratory flow (in liters/s), FIVI forced inspiratory volume in $1 \mathrm{~s}$ (in liters), TLCO diffusion capacity for carbon monoxide (in $\mathrm{mmol} / \mathrm{min} / \mathrm{kPa}$ ), $K C O$ diffusion capacity for carbon monoxide corrected for alveolar volume $(\mathrm{mmol} / \mathrm{min} / \mathrm{kPa} / \mathrm{liter})$

* Paired Wilcoxon $p<0.05$

** Paired Wilcoxon $p<0.01$

(Table 1). Three patients reported a history of asthma, of whom only one used pulmonary medication (budesonide). Three patients $(13.0 \%)$ had a history of pneumonia, including two out of the three patients with asthma. Shortly after participating in this study, one additional patient (no. 3) developed severe pneumonia, requiring mechanical ventilation and long-term rehabilitation. We included this patient in the further analyses on patients with a history of pneumonia. Fourteen patients $(60.9 \%)$ reported exertional dyspnea. Three patients (13.0\%), two current smokers and one patient with asthma, reported dyspnea at rest. Eleven patients $(47.8 \%)$ reported dysphagia, of whom three $(13.0 \%)$ also reported difficulty coughing.
Pulmonary function tests

The main finding was decreased expiratory and inspiratory muscle strength: PE-Max was $76.8 \%$ of the predicted value $(p=0.002)$ and PI-max 79.5\% $(p=0.004)$ (Table 2). Lower PE-Max\% pred was associated with lower PI-Max\% pred $(\rho=0.625, p=0.001)$ but also with lower IVC\% pred $(\rho=0.502, p=0.015)$ and lower PEF\% pred $(\rho=0.422, \quad p=0.045)$. IVC was also significantly decreased $(92.5 \%$ of predicted, $p=0.021)$, as were FEV1 (89.3\% of predicted, $p=0.003)$ and TLCO $(81.9 \%$ of predicted, $p=0.002$ ). The decreased TLCO is unlikely due to intrinsic lung disease, since the diffusion capacity 
corrected for alveolar volume (i.e., the $\mathrm{KCO}$ ) was normal $(97.9 \%$ of predicted, $p=0.26)$. Three patients had obstructive pulmonary disease (FEV1/IVC $<70 \%$ ), of whom two were former smokers and one a nonsmoker without a history of pulmonary disease. In these three patients, all other test results were within the same range as the rest of the cohort.

\section{Determinants of respiratory function}

Patients with limb girdle weakness had a lower PE-Max\% pred than patients with normal limb girdle strength $(62.6 \pm 26.1$ vs. $98.9 \pm 22.5 \%, p=0.005)$. Limb girdle weakness was not associated with any of the other outcomes. PEF\% pred was lower in patients who reported difficulty coughing $(74.3 \pm 9.5$ vs. $98.8 \pm 18.1 \%$, $p=0.028)$, as well as in patients with a history of pneumonia (76.6 \pm 9.0 vs. 99.7 vs. $18.3 \%, p=0.019)$. None of the other subjective complaints, demographic or clinical features were associated with any of the respiratory test results.

As to a possible genotype-phenotype relation, there were no differences in any of the respiratory test results between patients with mtDNA mutations or deletions and patients with POLG1 mutations, though there was a strong tendency toward a lower PE-Max\% pred in patients with mtDNA deletions $(66.4 \pm 31.0$ vs. $100.5 \pm 26.0 \%$, $p=0.064)$. In addition, all eight patients with a PE-Max below $65 \%$ of the predicted value had a mtDNA deletion.

\section{Discussion}

We found that both expiratory and inspiratory muscle strength was decreased in CPEO patients and that decreased respiratory muscle strength resulted in a decreased vital capacity, FEV1 and PEF. Respiratory muscle weakness was associated with limb girdle weakness, which is in concordance with studies in other myopathies [21, 22]. In contrast, there was no association between respiratory muscle function and other clinical features, disease duration, disease severity, subjective respiratory complaints or mutation type.

In the present study, we took several measures to include a representative cohort: our study was prospective and used strict clinical and genetic inclusion criteria. We also offered to perform the tests at the patients' homes, which resulted in a high participation rate. This not only enabled us to provide a representative overview of the prevalence and nature of respiratory involvement in CPEO, but also to identify possible determinants of respiratory involvement. The present results therefore not only confirm but also extend the conclusions of the previous smaller case studies on respiratory involvement in CPEO [3, 7, 15].

A major consequence of decreased respiratory muscle weakness in neuromuscular disorders is an increased risk of pneumonia [6]. CPEO patients may however be particularly prone to pneumonias because of concurrent laryngeal muscle weakness. Laryngeal muscle weakness can lead to aspiration of foods and to diminish glottic closure during coughing $[12,13,20]$. Inadequate glottic closure in turn, especially when combined with decreased inspiratory and expiratory strength, results in insufficient generation of intrathoracic pressure and thus in impaired expectoration.

In addition to an increased risk of pneumonia in CPEO, the course of pneumonia may theoretically also be more severe: a decreased ventilatory drive to hypoxia or hypercapnia predisposes to respiratory failure and prolonged weaning after mechanical ventilation $[3,7,19]$. In addition, CPEO patients may have trouble meeting the increased demands associated with infections because of limited metabolic and hemodynamic reserves [16].

Despite the fact that pneumonia is one of the main causes of death in CPEO, little is known about its prevention [2, 12]. As in other neuromuscular disorders, conservative treatment aimed at minimizing the risk of pneumonia seems rational [18]. This includes speech therapy and physiotherapy aimed at optimizing cough effectiveness and swallowing function, while a cricopharyngeal myotomy may be performed in selected cases of severe dysphagia [13]. Moreover, any sign of pneumonia or respiratory failure in a CPEO patient should prompt rapid diagnosis and treatment to prevent further complications.

The present study does not quantify the relative contributions of neurogenic or myogenic weakness of the respiratory muscles, nor the relative contribution of the various muscles involved in respiration. For instance we did not directly measure diaphragm strength, which ideally requires transdiaphragmic esophageal and gastric manometry. This is however an invasive procedure and carries a risk of aspiration. Alternative indicators for diaphragm strength are the nasal sniff pressure and the supine vital capacity. The use of supine vital capacity is however limited by the lack of normal values. Sniff pressure is mainly validated in amyotrophic lateral sclerosis and depends partly on the nasal airway conductance, while in patients with myopathies, PI-Max is possibly a more reliable indicator of inspiratory weakness than nasal pressure [24]. Therefore, in this study we used the PI-Max as an indicator of diaphragm strength, since it is also correlated to transdiaphragmic pressure [10]. 


\section{Conclusions}

Respiratory muscle weakness is common in CPEO patients. The presence of respiratory muscle weakness has important consequences for patient management, since it is associated with an increased risk of pneumonia and possibly of increased mortality. As there are no clinical predictors of respiratory muscle weakness and the rate of progression of respiratory muscle weakness has yet to be determined in a longitudinal study, we propose that periodic assessment of pulmonary function tests including respiratory muscle strength measurements should be included in evaluation of CPEO patients.

Conflict of interest Dr. van Engelen is research director of the European Neuromuscular Centre and receives institutional support from the Radboud University Nijmegen Medical Centre and the European Neuromuscular Centre, grant support from the Global FSH, The Netherlands Organization for Scientific Research, Prinses Beatrix Fonds and the Dutch FSHD Foundation.

Open Access This article is distributed under the terms of the Creative Commons Attribution Noncommercial License which permits any noncommercial use, distribution, and reproduction in any medium, provided the original author(s) and source are credited.

\section{References}

1. Arpa J, Cruz-Martinez A, Campos Y, Gutierrez-Molina M, Garcia-Rio F, Perez-Conde C, Martin MA, Rubio JC, Del Hoyo P, Arpa-Fernandez A, Arenas J (2003) Prevalence and progression of mitochondrial diseases: a study of 50 patients. Muscle Nerve 28:690-695

2. Aure K, de Ogier BH, Laforet P, Jardel C, Eymard B, Lombes A (2007) Chronic progressive ophthalmoplegia with large-scale mtDNA rearrangement: can we predict progression? Brain 130:1516-1524

3. Barohn RJ, Clanton T, Sahenk Z, Mendell JR (1990) Recurrent respiratory insufficiency and depressed ventilatory drive complicating mitochondrial myopathies. Neurology 40:103-106

4. Baul V, Deschauer M, Zierz S (2009) Chronic progressive external ophthalmoplegia-symptom or syndrome? Klin Monb Augenheilkd 226:822-828

5. Bindoff L, Brown G, Poulton J (1997) Mitochondrial myopathies. Diagnostic criteria for neuromuscular disorders, 2nd edn. Royal Society of Medicine Press Limited, London, pp 85-90

6. Braun NMT, Arora NS, Rochester DF (1983) Respiratory muscle and pulmonary function in polymyositis and other proximal myopathies. Thorax 38:616-623

7. Carroll JE, Zwillich C, Weil JV, Brooke MH (1976) Depressed ventilatory response in oculocraniosomatic neuromuscular disease. Neurology 26:140-146
8. Desnuelle C, Pellissier J-C, Serratrice G, Pouget J (1988) Chronic progressive external ophthalmoplegia (CPEO) associated with diaphragm paralysis: succesful treatment with Coenzyme Q (CoQ). Neurology 38:102-103

9. Fadic R, Russell JA, Vedanarayanan VV, Lehar M, Kuncl RW, Johns DR (1997) Sensory ataxic neuropathy as the presenting feature of a novel mitochondrial disease. Neurology 49:239-245

10. Heijdra YF, Dekhuijzen PN, van Herwaarden CL, Folgering HT (1993) Differences between sniff mouth pressures and static maximal inspiratory mouth pressures. Eur Respir J 4:541-546

11. Kim GW, Kim SM, Sunwoo IN, Chi JG (1991) Two cases of mitochondrial myopathy with predominant respiratory dysfunction. Yonsei Med J 32:184-189

12. Klopstock TM, Jaksch MM, Gasser TM (1999) Age and cause of death in mitochondrial diseases. Neurology 53:855-857

13. Kornblum CM, Broicher RM, Walther EM, Seibel PP, Reichmann HM, Klockgether TM, Herberhold CM, Schroder RM (2001) Cricopharyngeal achalasia is a common cause of dysphagia in patients with mtDNA deletions. Neurology 56:14091412

14. Lestienne P, Ponsot G (1988) Kearns-Sayre syndrome with muscle mitochondrial DNA deletion. Lancet 1:885

15. Manni R, Piccolo G, Banfi P, Cerveri I, Bruschi C, Zoia C, Tartara A (1991) Respiratory patterns during sleep in mitochondrial myopathies with ophthalmoplegia. Eur Neurol 31:12-17

16. Mehta $S$ (2006) Neuromuscular disease causing acute respiratory failure. Respir Care 51:1016-1021

17. Miller MR, Hankinson J, Brusasco V, Burgos F, Casaburi R, Coates A, Crapo R, Enright P, van der Grinten CPM, Gustafsson P, Jensen R, Johnson DC, MacIntyre N, Mckay R, Navajas D, Pedersen OF, Pellegrino R, Viegi G, Wanger J (2005) Standardisation of spirometry. Eur Respir J 26:319-338

18. Perrin C, Unterborn JN, D'Ambrosio C, Hill NS (2004) Pulmonary complications of chronic neuromuscular diseases and their management. Muscle Nerve 29:5-27

19. Sanaker PS, Husebye ES, Fondenes O, Bindoff LA (2007) Clinical evolution of Kearns-Sayre syndrome with polyendocrinopathy and respiratory failure. Acta Neurol Scand 115:64-67

20. Smith PEM, Calverley PMA, Edwards RHT, Evans GA, Campbell EJM (1987) Practical problems in the respiratory care of patients with muscular dystrophy. $\mathrm{N}$ Engl J Med 316: 1197-1205

21. Stubgen JP, Ras GJ, Schultz CM, Crowther G (1994) Lung and respiratory muscle function in limb-girdle muscular dystrophy. Thorax 49:61-65

22. Stubgen JP, Schultz C (2009) Lung and respiratory muscle function in facioscapulohumeral muscular dystrophy. Muscle Nerve 39:729-734

23. van Swieten JC, Koudstaal PJ, Visser MC, Schouten HJA, van Gijn J (1988) Interobserver agreement for the assessment of handicap in stroke patients. Stroke 19:604-607

24. Terzi N, Orlikowski D, Fermanian C, Lejaille M, Falaize L, Louis A, Raphael JC, Fauroux B, Lofaso F (2008) Measuring inspiratory muscle strength in neuromuscular disease: one test or two? Eur Respir J 1:93-98 